\title{
A bibliometric analysis of neuromarketing on web of science
}

DOI:10.36909/jer.12239

\author{
Feyza Gürbüz*, Sabiha Ünal ${ }^{*}$ \\ *Department of Industrial Engineering, Erciyes Universiy, Kayseri, 38039, Turkey. \\ ** Department of Industrial Engineering, Nuh Naci Yazgan Universiy, Kayseri, 38170, \\ Turkey.
}

Email: feyza@erciyes.edu.tr; sunal@nny.edu.tr

\begin{abstract}
The aim of the study within this framework, articles published on Neuromarketing between 2013 and 2018 were examined separately in the title and topic categories on the Web of Science (WOS) site and is aimed to analyse the status of the articles in the last 5 years. Articles with desired properties are parsed and internationally published articles have been reached. Before data is thrown into the CiteSpace V program, the implementation steps you will see on the next pages have been implemented individually. Bibliometric analysis was evaluated as visual, textual and statistical analysis by filling the relevant fields according to the results of the desired analysis. According to the number of citations in the studies, the author's name, country analysis of articles, institutions where authors work, article page numbers, publication type, research area, year of publication of articles, source title, and document type were examined.
\end{abstract}

Keywords: Bibliometric Analysis; CiteSpace V; Data Mining; Neuromarketing.

\section{INTRODUCTION}

Marketing is an economic and social process known as providing goods and services to individuals, families, groups and other organizations and meeting needs and wishes through 
change (Yücel \& Çubuk, 2013). The history of marketing goes back to history of humanity. The change in production processes over the years has also caused the change in trade and marketing. With the introduction of marketing in every field of our lives, Neuromarketing has entered the literature as one of the marketing methods by finding its use in the field of neurology, which is neuroscience, and adapting this method to marketing (Çubuk, 2012). Neuromarketing is the meeting of neurology and marketing in common ground, is a branch that measures the unconscious consumption behaviour of the consumer and creates a marketing strategy with the data obtained (Donthu, Kumar, Mukherjee, Pandey, \& Lim, 2021). Neuromarketing, which combine psychology, sociology, marketing and neurology, which are different disciplines, examines the "irrational" and "irrational decisions" of the consumer when making purchasing decisions (Çubuk, 2012). The product purchased or to be purchased is decided based on emotions and rationality is very low. In this case, it is almost impossible to measure the perception created by advertising in traditional ways. In fact, people often do not even realize this perception that has been created. Neuromarketing uses brain imaging methods to illustrate this link in purchasing decision.

The field of Neuromarketing has no very deep history. It is known that the first studies on this subject started in the 1990s and the studies carried out in those years were carried out in secret. In the 1990s, Prof. Gerry Zaltman of Harvard University first came to the fore in using the fMRI device in marketing research. However, the first person to define the concept of Neuromarketing is Prof. Ale Smidts. In Neuromarketing studies, two names come into prominence, Paul Lauterbur and Peter Mansfield (Ural, 2008). These two doctors have done many studies with MRI techniques and these studies have contributed greatly to Neuromarketing (Veronica, 2009). The most important feature of Neuromarketing is that it has more reliable results than the answers given by traditionally applied surveys and focus groups (Çubuk, 2012). Neuromarketing does not include verbal data. People's brain imaging 
is done, and these are analysed based on response to stimuli. With these methods, instead of verbal expressions of people, areas of activity in their brains are examined. In this case, people are less likely to lie. When Neuromarketing and traditional marketing are used together, the results are more efficient and reliable. It is possible to see Neuromarketing applications in many different fields when the literature about Neuromarketing is researched. Golnar-Nik P., Farashi S., and Safari MS has conducted a study on the prediction of consumers' preference, and the interpretation of the alteration of consumers' decision-making in shopping behaviour when the content of an advertisement including background colour and promotions was changed (Golnar-Nik, Farashi, \& Safari, 2019). Akan's study examined the conceptual evaluation of Neuromarketing as a new interdisciplinary area and the techniques used in Neuromarketing studies and their uses (Akan, 2018). Zhang J., Ho Yun J., and Lee EJ investigated the neural indicators of engagement with content as driver of consumers' clickthrough behaviour in social media (Zhang, Ho Yun, \& Lee, 2020). Zeshui Xu, Xindi Wang, Xinxin Wang, Marinko Skare performed bibliometric analysis with 1044 data drawn from WOS between 1984 and 2020 to explain the relationships between entrepreneurship and crisis (Xu, Wang, Wang, \& Skare, 2021).

\section{METHOD}

Advances in the collection and storage of digital data have led to the exponential growth of the stored data. The rapid growth and integration of databases provides scientists, engineers, and business people with a vast new resource that can be analysed to make scientific discoveries, optimize industrial systems, and uncover financially valuable patterns. To undertake these large data analysis projects, researchers and practitioners have adopted established algorithms from statistics, machine learning, neural networks, and databases and 
have also developed new methods targeted at large data mining problems (Hand, Mannila, \& Smyth, 2001).

As part of the study, articles related to Neuromarketing on the Web of Science site have been scanned and reviewed. Web of Science is a website that allows us to Access the most relevant and prestigious publications in our research area by regularly scanning journals and conference papers on Science, Social Science and Humanities. WOS links to all related records using reference information and subject relationships in the work of expert researchers who produce publications in our research area.

Articles with the desired feature through the Web of Science are listed according to specifications such as the author's name, the country the article published, the institutions the author works with, the article page numbers, the type of publication, the research area, the year the article was published, the source title, the document type, the number of citations. The listed articles are transferred to the CiteSpace V program in file format and bibliometric analysis is started. CiteSpace V is free java-based software that can be used to visualize scientific publications, analyse trends and models. The program, written to visualize areas of knowledge within disciplines, can be used to discover critical points in a specific area. By interpreting the networks created through the CiteSpace program, it is possible to reveal the dissemination points and historical transformation of information about the scientific field, the issues that are rapidly rising, and the publications of critical importance in the field. Web of Science data is used as the main data source in the program where various data such as keywords, authors, institutions, citations can be analysed (UZGORU, 2016).

In the bibliometric analysis of article, the year that the article was published, the author's name, the institution in which the author worked, the use of article titles, the countries in which the articles were published, the number of article pages, etc. features were analysed in two different categories as topic and title. Within the scope of the research, the publication 
types of the articles, the years they were published, the research fields, the type of the documents, the source titles, the total number of citations, the number of pages, the institutions where the authors worked, the country they were collected from, the names of the authors were analysed.

\section{FINDINGS AND RESULTS}

\section{Review Based on the Title Category}

The data provided from the Web of Science website was analysed under two different headings by transferring it to the CiteSpace V program. Primarily, articles related to Neuromarketing were handled in the "Title" category and the results are shown in Figure 1.

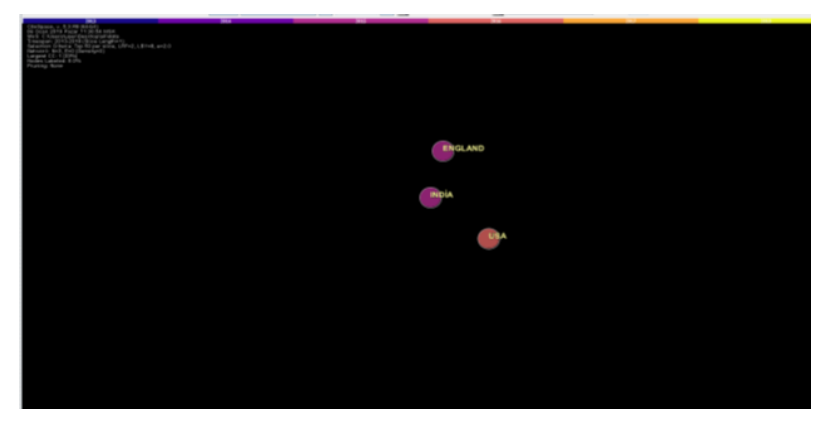

(a)

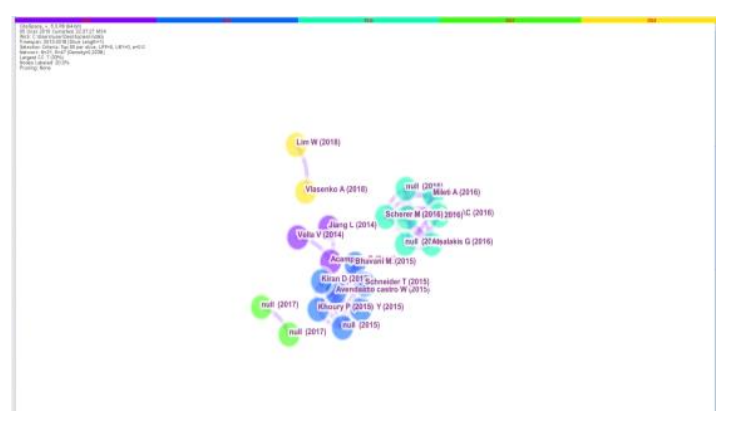

(b)

Figure 1 The distribution of the countries (a) and authors (b) of the articles on

Neuromarketing by years in the Title category

Authors who wrote articles on Neuromarketing reviewed, and Kim Jongha is the author who writes the most articles on Neuromarketing when bibliometric analyses of articles are done. The author mentions the attention concentration tendencies of one subject who showed convergent exploratory acts actively through the gaze- brainwave measurement experiment of café space images in "A Study on the Attention Concentration Properties in Convergent Exploration Situations in Café Space -Focusing on Gaze and Brainwave Data Analysis" 
(Jong-Ha, Ju-Yeon, \& Sang-Hee, 2016). The second rank is two names. These are Kim Young Kab and Ko Euisuk. The other authors are shown in Table 1.

Table 1 The distribution of authors by number of articles published, on Title category (JongHa, Ju-Yeon, \& Sang-Hee, 2016) (Park, Kim, \& Baik, 2016) (Atsalakis, Frantzis, \& Zopounidis, 2016)

\begin{tabular}{|c|c|c|c|}
\hline Authors & Percentage & Authors & Percentage \\
\hline KIM JONGHA & $16.667 \%$ & ATSALAKIS G & $5.556 \%$ \\
\hline $\begin{array}{c}\text { KIM YOUNG } \\
\text { KAB }\end{array}$ & $11.111 \%$ & AVENDANO & $5.556 \%$ \\
\hline KO EUISUK & $11.111 \%$ & CASTRO WILLIAM & \\
\hline
\end{tabular}

When the countries that published articles on Neuromarketing were examined, India ranks as first. Subsequently, England, Malaysia, and the USA share a second rank. The other countries are shown in Table 2.

Table 2 The distribution of articles by countries in which they are collected, on Title category

\begin{tabular}{|c|c|c|c|}
\hline Countries & Percentage & Countries & Percentage \\
\hline INDIA & $16.667 \%$ & MALAYSIA & $11.111 \%$ \\
\hline ENGLAND & $11.111 \%$ & USA & $11.111 \%$ \\
\hline
\end{tabular}

Data has been extracted which countries the authors of the articles work, and Anna University takes first place. The ranking of the other institutions by percentages is shown in Table 3 .

Table 3 The distribution of institutions where authors work, on Title category

\begin{tabular}{|c|c|}
\hline Institutions & Percentage \\
\hline ANNA UNIVERSITY & $6.112 \%$ \\
\hline CHARLEMAGNE CAPITAL & $5.556 \%$ \\
\hline ESCUELA SUPER POLITECN CHIMBORAZO & $5.556 \%$ \\
\hline IT STEP UNIV & $5.556 \%$ \\
\hline JADAVPUR UNIVERSITY & $5.556 \%$ \\
\hline
\end{tabular}


When the type of publication of articles is examined, the type of publication in which the most articles are published is "Journal". The list is followed by "Serial" as a type of publication. Analysis of articles by publication type is shown in Table 4.

Table 4 The distribution of articles by publication type, on Title category

\begin{tabular}{|c|c|}
\hline Type of Publication & Percentage \\
\hline J (Journal) & $57.1428 \%$ \\
\hline S (Serial) & $28.5714 \%$ \\
\hline B (Book) & $14.2857 \%$ \\
\hline
\end{tabular}

When analysing the years in which articles were written, the most articles related to Neuromarketing were written in 2015 and 2016. In these years, a total of 7 articles were written. The distribution of articles by the years in which they were written is shown in Table 5.

Table 5 The distribution of articles by year in which they were written, on Title category

\begin{tabular}{|c|c|c|c|}
\hline Years & Article Numbers & Years & Article Numbers \\
\hline 2018 & 2 & 2015 & 7 \\
\hline 2017 & 2 & 2014 & 3 \\
\hline 2016 & 7 & Total & 21 \\
\hline
\end{tabular}

Among the most researched areas in Neuromarketing, "Business Economics" ranks first. Then, the area's most articles written are "Engineering" and "Computer Science". The distribution of articles by research areas is shown in Table 6 .

Table 6 The distribution of articles by research areas, on Title category

\begin{tabular}{|c|c|c|c|}
\hline Research Areas & Percentage & Research Areas & Percentage \\
\hline $\begin{array}{c}\text { BUSINESS } \\
\text { ECONOMICS }\end{array}$ & $33.333 \%$ & MATHEMATICS & $22.222 \%$ \\
\hline COMPUTER SCIENCE & $27.778 \%$ & ENERGY FUELS & $11.111 \%$ \\
\hline ENGINEERING & $27.778 \%$ & SPORT SCIENCES & $11.111 \%$ \\
\hline
\end{tabular}


When articles are examined, "Article" takes the first place as a document type. The distribution of articles by document type is shown in Table 7 .

Table 7 The distribution of articles by document type, on Title category

\begin{tabular}{|c|c|}
\hline Document Types & Percentage \\
\hline ARTICLE & $61.111 \%$ \\
\hline MEETING & $33.333 \%$ \\
\hline EDITORIAL & $5.556 \%$ \\
\hline
\end{tabular}

When the source titles of the articles are examined, "Lecture Notes in Computer Science" and "Science of Emotional Sensibility" share the top of the list. The distribution of articles by source title is shown in Table 8.

Table 8 The distribution of articles by source title, on Title category

\begin{tabular}{|c|c|}
\hline Source Titles & Percentage \\
\hline LECTURE NOTES IN COMPUTER SCIENCE & $11.111 \%$ \\
\hline SCIENCE OF EMOTION SENSIBILITY & $11.111 \%$ \\
\hline 2015 ANNUAL IEEE INDIA CONFERENCE INDICON & $5.556 \%$ \\
\hline $\begin{array}{c}\text { 2018 IEEE SECOND INTERNATIONAL CONFERENCE ON } \\
\text { DATA STREAM MINING PROCESSING DSMP }\end{array}$ & $5.556 \%$ \\
\hline ANNUAL IEEE INDIA CONFERENCE & $5.556 \%$ \\
\hline
\end{tabular}

When articles were analysed according to the number of pages in the "Title" category, the article with the highest number of pages was published in 2014. This article belongs to Acampora. Article density by number of pages is centred in the range of 300 to 400 pages. Analysis of the number of pages of articles by year is shown in Table 9.

Table 9 Analysis of the number of pages of articles by year, on Title category

\begin{tabular}{|c|c|c|c|}
\hline Number of Pages & Year of Release & $\begin{array}{c}\text { Number of } \\
\text { Pages }\end{array}$ & $\begin{array}{c}\text { Year of } \\
\text { Release }\end{array}$ \\
\hline
\end{tabular}




\begin{tabular}{|c|c|c|c|}
\hline $881-887$ & 2014 & $352-355$ & 2018 \\
\hline $570-576$ & 2016 & $245-269$ & 2016 \\
\hline $389-399$ & 2015 & $251-259$ & 2018 \\
\hline $373-385$ & 2015 & $170-187$ & 2014 \\
\hline
\end{tabular}

When the number of citations of articles is examined, there is an article written by Vella $\mathrm{N}$. in 2014 with 10 references. Analysis of the total number of citations of articles by year is shown in Table 10.

Table 10 Analysis of the total number of citations of articles by year, on Title category

\begin{tabular}{|c|c|}
\hline Number of Citations & Year of Release \\
\hline 10 & 2014 \\
\hline 7 & 2016 \\
\hline
\end{tabular}

Subsequently, articles related to Neuromarketing were handled in the "Topic" category and the results are shown in Figure 2.
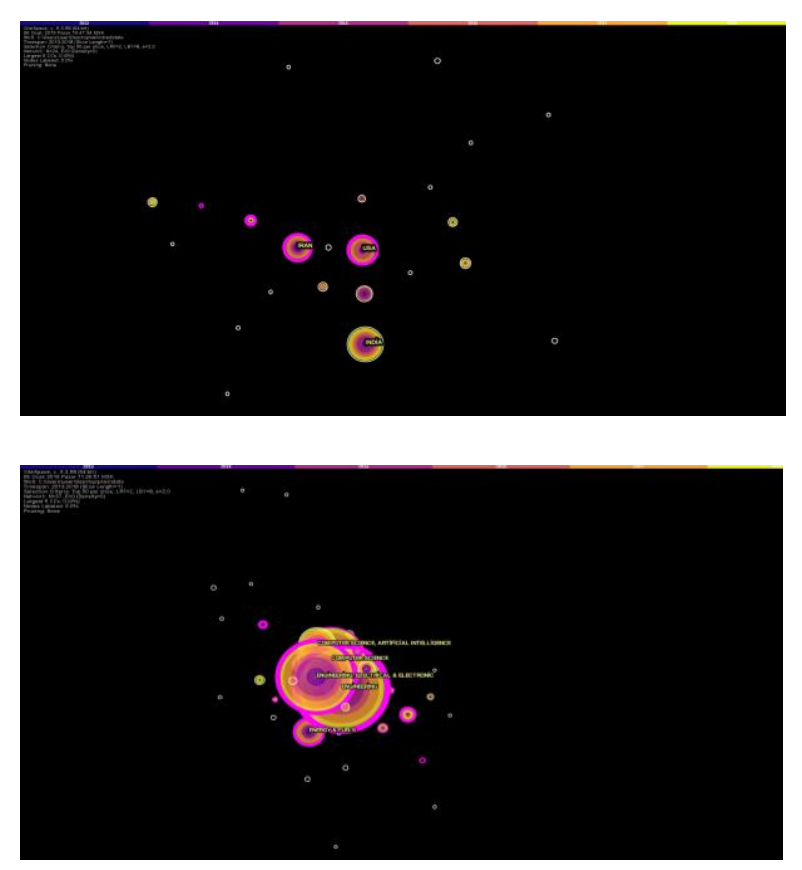

(a)

(b)

Figure 2 The distribution of the countries (a) and research field (b) of the articles on

Neuromarketing by years in the Topic category 


\section{Review Based on the Topic Category}

Data taken through the Web of Science is also examined under the category "Topic", and when the data examined, Kim Jongha is the author with the most articles on Neuromarketing in the "Topic" category as well as in the "Title" category. This time, the second rank is shared by 5 authors on this subject. These authors are Atsalakis G., Catalao JPS, Kim Young Kab, Rajab S., and Sharma V. The other authors are shown in Table 11.

Table 11 The distribution of authors by number of articles published, on Topic category (Jong-Ha, Ju-Yeon, \& Sang-Hee, 2016) (Park, Kim, \& Baik, 2016) (Atsalakis, Frantzis, \& Zopounidis, 2016) (Cartocci, et al., 2017)

\begin{tabular}{|c|c|c|c|}
\hline Authors & Percentage & Authors & Percentage \\
\hline KIM JONGHA & $6.8965 \%$ & KIM YOUNG KAB & $5.1724 \%$ \\
\hline ATSALAKIS G & $5.1724 \%$ & AMJADY N & $3.4483 \%$ \\
\hline CATALAO J P S & $5.1724 \%$ & BABILONI F & $3.4483 \%$ \\
\hline
\end{tabular}

When countries are examined, India ranks as first, as in the "Title" category. India is followed by the USA and Iran. The ranking of the other countries is shown in Table 12.

Table 12 The distribution of articles by countries in which they are collected, on Topic category

\begin{tabular}{|c|c|c|c|}
\hline Countries & Percentage & Countries & Percentage \\
\hline INDIA & $14.205 \%$ & ENGLAND & $5.682 \%$ \\
\hline IRAN & $9.091 \%$ & MALAYSIA & $5.682 \%$ \\
\hline USA & $9.091 \%$ & ITALY & $5.114 \%$ \\
\hline CHINA & $6.818 \%$ & TURKEY & $5.114 \%$ \\
\hline
\end{tabular}

When the data on which universities the authors of articles work in are examined, Nanyang Tec University ranks as first. In the second rank is Islamic Azad University. The ranking of the other institutions by percentages is shown in Table 13. 
Table 13 The distribution of institutions where authors work, on Topic category

\begin{tabular}{|c|c|}
\hline Institutions & Percentage \\
\hline $\begin{array}{c}\text { NANYANG TECHNOLOGICAL } \\
\text { UNIVERSITY }\end{array}$ & $4.546 \%$ \\
\hline ISLAMIC AZAD UNIVERSITY & $3.977 \%$ \\
\hline BRNO UNIVERSITY OF TECHNOLOGY & $1.705 \%$ \\
\hline INESC & $1.705 \%$ \\
\hline SAPIENZA UNIVERSITY ROME & $1.705 \%$ \\
\hline
\end{tabular}

When the type of publication of Neuromarketing articles is examined, the type of publication in which 115 articles are published is "Journal". Analysis of articles by publication type is shown in Table 14.

Table 14 The distribution of articles by publication type, on Topic category

\begin{tabular}{|c|c|}
\hline Type of Publication & Percentage \\
\hline J (Journal) & 115 \\
\hline S (Serial) & 31 \\
\hline B (Book) & 30 \\
\hline
\end{tabular}

2013 is at the top of the list with 53 articles, when years with the most articles written are examined. This ranking is followed by 2016 with 49 articles. The distribution of articles by the years in which they were written is shown in Table 15.

Table 15 The distribution of articles by year in which they were written, on Topic category

\begin{tabular}{|c|c|l|c|}
\hline Years & Article Numbers & Years & Article Numbers \\
\hline 2017 & 53 & 2018 & 29 \\
\hline 2016 & 49 & 2019 & 1 \\
\hline 2015 & 44 & Total & 176 \\
\hline
\end{tabular}

"Computer Science" ranks first among the most researched areas in Neuromarketing. "Computer Science" field constitutes $48.9 \%$ of articles written about Neuromarketing. Later, 
the field with the most articles written is "Engineering". The distribution of articles by research areas is shown in Table 16.

Table 16 The distribution of articles by research areas, on Topic category

\begin{tabular}{|c|c|c|c|}
\hline Research Areas & Percentage & Research Areas & Percentage \\
\hline COMPUTER SCIENCE & $48.864 \%$ & MATHEMATICS & $30.682 \%$ \\
\hline ENGINEERING & $42.045 \%$ & ENERGY FUELS & $15.341 \%$ \\
\hline BUSINESS & $38.068 \%$ & AUTOMATION & $12.500 \%$ \\
ECONOMICS & & CONTROL SYSTEMS & \\
\hline
\end{tabular}

"Article", as a document type, ranks as first. The distribution of the other articles by document type is shown in Table 17.

Table 17 The distribution of articles by document type, on Topic category

\begin{tabular}{|c|c|c|c|}
\hline Document Types & Percentage & Document Types & Percentage \\
\hline ARTICLE & $68.750 \%$ & OTHER & $5.114 \%$ \\
\hline MEETING & $35.795 \%$ & REVIEW & $5.114 \%$ \\
\hline
\end{tabular}

When the source title of articles is examined, the title "Aip Conference Proceedings" takes first rank. The distribution of articles by source title is shown in Table 18 .

Table 18 The distribution of articles by source title, on Topic category

\begin{tabular}{|c|c|}
\hline Source Titles & Percentage \\
\hline AIP CONFERENCE PROCEEDINGS & $2.273 \%$ \\
\hline APPLIED SOFT COMPUTING & $1.705 \%$ \\
\hline EXPERT SYSTEMS WITH APPLICATIONS & $1.705 \%$ \\
\hline LECTURE NOTES IN COMPUTER SCIENCE & $1.705 \%$ \\
\hline
\end{tabular}

When the number of pages of articles is examined, the article with the highest number of pages was written by Congleton in 2014. Articles are usually written between 3000 and 5000 pages per year. Analysis of the number of pages of articles by year is shown in Table 19. 
Table 19 Analysis of the number of pages of articles by year, on Topic category

\begin{tabular}{|c|c|c|c|}
\hline $\begin{array}{c}\text { Number of } \\
\text { Pages }\end{array}$ & Year of Release & $\begin{array}{c}\text { Number of } \\
\text { Pages }\end{array}$ & Year of Release \\
\hline $10432-10438$ & 2014 & $4173-4191$ & 2016 \\
\hline $4813-4832$ & 2015 & $3851-3868$ & 2017 \\
\hline $4654-4661$ & 2016 & $3360-3372$ & 2017 \\
\hline $4273-4287$ & 2018 & $3349-3373$ & 2015 \\
\hline
\end{tabular}

When the citation numbers of the articles were examined, it was observed that the first-ranked article was published by Congleton in 2014 .

\section{CONCLUSION}

The study includes analysing the results by researching articles published internationally on Neuromarketing between 2013 and 2018 with specific criteria. At the same time, the methodology of bibliometric analysis was explained in this study, the literature on Neuromarketing was synthesized and summarized. The term Neuromarketing was scanned separately in both Title and Topic categories on the Web of Science site, and 21 articles in the Title category and 176 articles in the Topic category were reviewed. This review provides the opportunity to evaluate status of literature, development process and problems of the field writing on Neuromarketing. The term Neuromarketing appears to have increased articles in the Title category in 2015 and 2016, but in later years it decreased in an unknown way. At a time when scientific developments are progressing very quickly and these and similar topics are becoming more important, more articles should be published, but the reason for such a decline is a matter of curiosity. Based on the information obtained in the results of the review, Kim Jongha is the author who wrote the most articles and contributed to the subject of Neuromarketing. The articles scanned in the Title category have the most research areas: "Business Economics" and "Engineering", while the most research areas of the articles scanned in the Topic category are "Computer Science" and "Engineering" determined. The 
most published type of article publication on this topic is "Journal" in both categories. "India" ranks first in both categories when the countries where the articles are collected are examined. The reason is that the institutions in which the authors work may be in India.

Bibliometric analysis studies are carried out with the data obtained while performing the analysis. For this reason, it is inevitable that the bibliometric data added to the database after the analysis will constantly affect the results of the analysis. However, the purpose and importance of the study is revealed here. The results of the analysis are supported by examining the data not only in one of the subjects and title categories, but also under different sub-headings in both categories. Despite these limitations, bibliometric analysis is a retrospective study and supports both academics and researchers working on the subject.

\section{REFERENCES}

A.Stasi, G. Songa, M.Mauri, A.Ciceri, F.Diotallevi, G. Nardone, V.Russo. 2018. Neuromarketing empirical approaches and food choice: A systematic seview. Food Research International. Volume 108: 650-664.

Akan, Ş. A. 2018. Conceptual evaluation on neuromarketing as a new multidisciplinary field. Black Sea Journal of Public and Social Science 1(1): 20-25.

Atsalakis, G., Frantzis, D., Zopounidis, C. 2016. Commodities' price trend forecasting by a neuro-fuzzy controller. Energy Systems-Optimization Modeling Simulation and Economic Aspects. 7(1): 73-102 DOI: 10.1007/s12667-015-0154-8.

\section{Cartocci, G., Caratu, M., Modica, E., Maglione, A.G., Rossi, D., Cherubino, P., Babiloni,} F., 2017. Electroencephalographic, heart rate, and galvanic skin response assessment for an advertising perception study: Application to antismoking public service announcements. Journal of Visualized Experiments. 126: e55872, DOI: 10.3791/55872. 
Çubuk, F. 2012. A new approach to implementation in marketing: Neuromarketing [thesis], Turkey (İstanbul): Kadir Has University.

Donthu, N., Kumar, S., Mukherjee, D., Pandey, N., Lim, W.M. 2021. How to conduct a bibliometric analysis: An overview and guidelines. Journal of Business Research. Volume 133: $285-296$.

Golnar-Nik, P., Farashi, S., Safari, MS. 2019. The application of EEG power for the prediction and interpretation of consumer decision-making: A neuromarketing study. Physiology \& Behavior. Volume 207: 90-98.

Hand, D., Mannila, H. \& Smyth, P. 2001. Principles of data mining. MIT Press, Cambridge, MA.

http://cabim.ulakbim.gov.tr/wp-content/uploads/sites/4/2016/12/web-of-science-sc1-exp.ssc1-ahc1-veri-taban\%c4\%b1nda-yay\%c4\%b1n-taramas\%c4\%b1-nas\%c4\%b11yap\%c4\%b11\%c4\%b1r.pdf

http://uzgoru.ikc.edu.tr/S/15006/citespace

Jong-Ha, K., Ju-Yeon, K., Sang-Hee K. 2016. A study on the attention concentration properties in convergent exploration situations in cafe space- focusing on gaze and brain wave data analysis-. Korean Institute of Interior Design Journal. 25(2): 30-40. 10.14774/JKIID.2016.25.2.030.

Park, S.M., Kim, Y.G., Baik, D.K. 2016. Sentiment root cause analysis on fuzzy formal concept analysis and fuzzy cognitive map. Journal of Computing and Information Science in Engineering 16(3); 031004, DOI: 10.1115/1.4034033.

Ural, Y. 2018. New approach to marketing: A theoretical assessment of neuromarketing. Cukurova University Journal of Institute of Social Science. 17(2): 432-421. 
Xu, Z., Wang, X., Wang, X., Skare, M. 2021. A comprehensive bibliometric analysis of entrepreneurship and crisis literature published from 1984 to 2020. Journal of Business Research. Volume 135: 304-318.

Veronica, B. 2009. Brief history neuromarketing, The International Conference on Administration and Business, 14-15, Romania.

Yücel, A, Çubuk F. 2013. Comparison of neuromarketing and subconscious advertising approaches. Nigde University Journal of the Faculty of Economics and Administrative Science. 6(2): 183-172.

Zhang, J., Ho Yun, J., Lee, EJ. 2020. Brain buzz for Facebook? Neural indicators of SNS content engagement. Journal of Business Research. 